\title{
Purchase intention towards dietary supplements during COVID-19 pandemic: consumers' perspective
}

\author{
${ }^{1}$ Wong, Y.Q., ${ }^{1, *}$ Tan, B.C., ${ }^{2}$ Lau, T.C. and ${ }^{1}$ Khan, N. \\ ${ }^{1}$ Multimedia University, Faculty of Management, Persiaran Multimedia, 63100 Cyberjaya, Selangor, \\ Malaysia \\ ${ }^{2}$ Business School, UCSI University, UCSI Heights, 1, Jalan Puncak Menara Gading, Taman Connaught, \\ 56000 Cheras, Kuala Lumpur, Malaysia.
}

\author{
Article history: \\ Received: 16 April 2021 \\ Received in revised form: 7 \\ May 2021 \\ Accepted: 10 July 2021 \\ Available Online: 30 October \\ 2021
}

Keywords:

Attitude,

Dietary Supplement,

Health Consciousness,

Intention,

Pandemic,

Price

DOI:

https://doi.org/10.26656/fr.2017.5(5).270

\begin{abstract}
The consumption of dietary supplements (DSs) has been steadily increasing in the wake of the COVID-19 outbreak in most countries. Consumer purchase intention towards DSs is expected to be of concern to many companies in the pharmaceutical industry. This study extends the Theory of Planned Behaviour by adding health consciousness and perceived price in the model to investigate its effect on consumer purchase intention towards DSs during the COVID-19 outbreak. A questionnaire-based survey was distributed via an online survey to 207 respondents. Results from multiple regression analysis revealed that consumer attitudes, subjective norms, perceived behavioural control, and health consciousness contributed significantly to purchase intention towards DSs. Perceived price did not have an impact on intention. Further investigation revealed that favourable attitudes towards DSs were the most important contributor towards purchasing DSs during the COVID-19 pandemic.
\end{abstract}

\section{Introduction}

Despite poor business operations and a low level of acceptance by customers, the demand for dietary supplements (DSs) continues to expand steadily each year (Birruntha, 2019). Interest in immunity-positioned vitamins and DSs have grown significantly since the start of the COVID-19 pandemic, as many customers look for products that offer the promise of broad disease prevention (Parikh et al., 2020). Unlike other consumer health products, immunity types of products sustained global interest even after the initial wave of panicinduced stockpiling in the first weeks of the crisis, with strong growth continuing into the second half of 2020.

Generally, the market size of DSs has seen an increase in Malaysia (Birruntha, 2019). Vitamin supplements, the mineral form of supplement products, calcium, omega 3 fish oil products, and botanicals are popular DSs (Phillips and Rimmer, 2013). The historical market size of multi-vitamins consumption of DSs in Malaysia grows steadily from RM 2.22Bil in 2015 to RM3.57Bil in 2020 (Euromonitor, 2019b). Nevertheless, previous research on factors affecting the decision to purchase DSs is still under-explored in Malaysia. In addition, the COVID-19 treatment options have raised many concerns among populations across the world (International Monetary Fund, 2020), leading to many attempts to find alternative options to prevent the spread of the disease or to mitigate the progression of the infection, including a greater emphasis on preventive measures to improve immunity and minimize the risk of infection (Alyami et al., 2020).

In the context of consumer behavioural study related to the DSs, the Theory of Planned Behaviour (TPB) (Ajzen,1991) has been commonly applied over the years (Petraszko, 2013; Noor et al., 2014; Lee et al., 2016; Tan et al., 2019; Alami et al., 2019). TPB mainly consisted of three core components, namely, attitude, subjective norms, and perceived behavioural control, together influence an individual's behavioural intention. Attitude contributed to the Dss purchase intention significantly (Lee et al., 2016; Tan et al., 2019). Noor et al. (2014) revealed that consumers who displayed an optimistic attitude to consume DSs believed that it could enhance their health and may have a higher intention to consume DSs. Besides, Petraszko (2013) showed that subjective norms did not support the behavioural intention of sports women's decision to increase their intake of multivitamins. In addition, Noor et al. (2014) revealed that perceived behavioural control has positive effects on 
behavioural intention towards DSs; and Petraszko (2013) and Alami et al. (2019) found perceived behavioural control to be positively related to the behavioural intention to consume vitamin and minerals respectively. In Malaysia, Tan et al. (2019) reported that perceived behavioural control and health consciousness were able to influence the purchase intention of consumers towards health supplement products. In contrast, Michaelidou and Hassan (2008) discovered that consciousness of wellbeing is the least important reason for the intention to buy organic food. Another study also shows that priceconsciousness has a significant effect on consumers purchase intention of DSs (Ezlika et al., 2014; Wongsawasdi, 2016).

Nevertheless, all the previous studies were conducted prior to the COVID-19 outbreak, hence the importance of the current research in looking at the different perspectives. Therefore, this study aims to extend the Theory of Planned Behaviour (TPB) by adding the additional two variables, namely, health consciousness and perceived price in the model to predict consumer purchase intention towards the DSs during the Covid pandemic outbreak. The outcome of this study will assist pharmaceutical firms in implementing their marketing strategies to promote DSs products to the right target market more effectively.

\section{Methodology}

\subsection{Research framework and hypotheses}

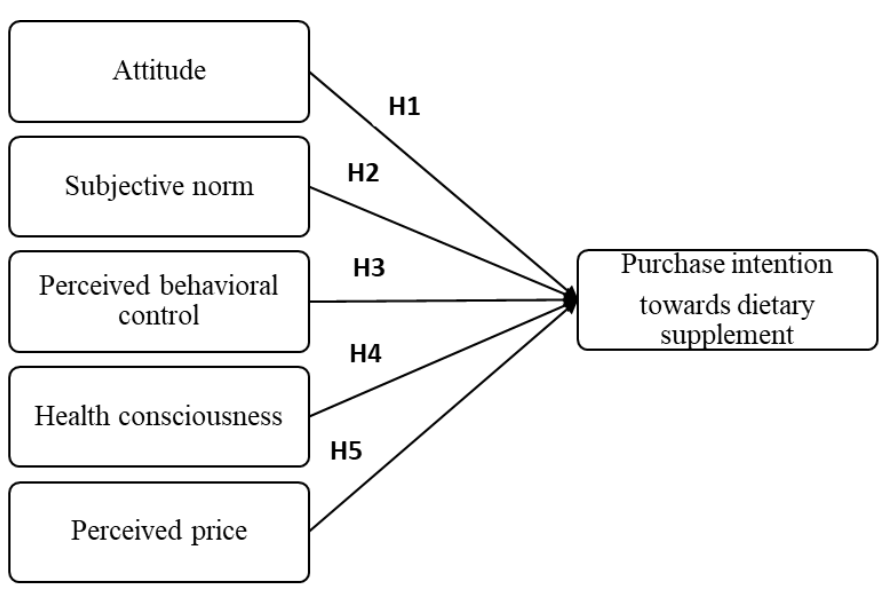

Figure 1. Research framework

Figure 1 illustrated a proposed research framework by adding the variables of health consciousness and perceived price to the TPB model. The following hypotheses were proposed:

H1. There is a significant relationship between attitude and purchase intention towards DSs.

$\mathrm{H} 2$. There is a significant relationship between subjective norms and purchase intention towards DSs.

H3. There is a significant relationship between perceived behavioural control and purchase intention towards DSs.

H4. There is a significant relationship between health consciousness and purchase intention towards DSs.

H5. There is a significant relationship between perceived price and purchase intention towards DSs.

\subsection{Research methods}

In this study, the survey instruments of purchase intention (5 items) were adopted from Udomkitmongkol (2016) and Lee et al. (2016), attitude (5 items) was adopted from Udomkitmongkol (2016), subjective norm (6 items) and perceived behavioural control (5 items) were adopted from Shen and Chen (2020) respectively. Besides, 8 items used to measure health consciousness were adopted from Plank and Gould (1990); while 6 items used to measure perceived price were adopted from Alford and Biswas (2002), Noh et al. (2013), and Udomkitmongkol (2016). All items were measured using a five-point Likert scale. In terms of the method used to collect the data, survey questionnaires were conducted via a social media platform. The questionnaire was prepared online and circulated to 207 respondents. Data collected from respondents' self-administered questionnaires were analysed with SPSS version 21 software. Data analysis conducted were descriptive analysis, factor analysis, reliability analysis, and multiple linear regression analysis.

\section{Results}

\subsection{Descriptive analysis}

From the collected sample ( $\mathrm{N}=207), 45.4 \%$ of the respondents were female, $53.6 \%$ were in the age group of $31-40$ years, $71.5 \%$ obtained a bachelor degree qualification and $36.7 \%$ earned the monthly income of RM3,001-RM5,000. In terms of occupational level, the majority of respondents were executives working in the private sector $(76.3 \%)$, followed by students $(9.2 \%)$. Besides, $66.2 \%$ of respondents were Chinese and $62.3 \%$ were married. With regards to the existing DSs consumption and purchase behaviour, $41.1 \%$ of the respondents were taking DSs daily and $59.9 \%$ bought supplements in the last 3 months. A total of $40.1 \%$ indicated no history of buying DSs.

\subsection{Factor analysis}

The details of the results for the factor analysis and scale reliabilities are presented in Table 1. The KMO measure of sampling adequacy for each of the constructs was greater than 0.6, indicating sufficient intercorrelations of Bartlett's Test of Sphericity (Hair et al., 2010), which was found to be significant $(0.000$, sig.< 0.05). Thus, the sample size of 207 was adequate and satisfactory in this study. The Cronbach alpha for each 
factor was greater than 0.60 (range from 0.650 to 0.940 ) which means that the scale scores for each of the factors were reasonably reliable (Hair et al., 2010). The factor loadings of all the items were above 0.50, except SN1, SN4 and PP6. These three items were eventually removed due to low commonalities $(<0.50)$.

Table 1. Results of the factor analysis and scale reliabilities

\begin{tabular}{|c|c|c|c|c|}
\hline Construct & Items & $\begin{array}{c}\text { Factor } \\
\text { Loading }\end{array}$ & $\mathrm{KMO}$ & $\begin{array}{l}\text { Alpha } \\
\text { Value }\end{array}$ \\
\hline \multirow{5}{*}{ Attitudes } & A1 & 0.842 & 0.71 & 0.726 \\
\hline & A2 & 0.83 & & \\
\hline & A3 & 0.846 & & \\
\hline & A4 & 0.822 & & \\
\hline & A5 & 0.667 & & \\
\hline \multirow{4}{*}{$\begin{array}{l}\text { Subjective } \\
\text { Norm }\end{array}$} & SN2 & 0.78 & 0.613 & 0.65 \\
\hline & SN3 & 0.635 & & \\
\hline & SN5 & 0.865 & & \\
\hline & SN6 & 0.876 & & \\
\hline \multirow{5}{*}{$\begin{array}{l}\text { Perceived } \\
\text { Behavioural } \\
\text { Control }\end{array}$} & PBC1 & 0.522 & 0.755 & 0.754 \\
\hline & PBC2 & 0.636 & & \\
\hline & $\mathrm{PBC} 3$ & 0.658 & & \\
\hline & PBC4 & 0.689 & & \\
\hline & PBC5 & 0.653 & & \\
\hline \multirow{8}{*}{$\begin{array}{c}\text { Health } \\
\text { Consciousness }\end{array}$} & $\mathrm{HC} 1$ & 0.78 & 0.928 & 0.94 \\
\hline & $\mathrm{HC} 2$ & 0.779 & & \\
\hline & $\mathrm{HC} 3$ & 0.8 & & \\
\hline & $\mathrm{HC} 4$ & 0.885 & & \\
\hline & $\mathrm{HC} 5$ & 0.886 & & \\
\hline & HC6 & 0.86 & & \\
\hline & $\mathrm{HC7}$ & 0.817 & & \\
\hline & $\mathrm{HC} 8$ & 0.859 & & \\
\hline \multirow{5}{*}{$\begin{array}{l}\text { Perceived } \\
\text { Price }\end{array}$} & PP1 & 0.554 & 0.784 & 0.787 \\
\hline & PP2 & 0.82 & & \\
\hline & PP3 & 0.811 & & \\
\hline & PP4 & 0.818 & & \\
\hline & PP5 & 0.775 & & \\
\hline \multirow{5}{*}{$\begin{array}{l}\text { Purchase } \\
\text { Intention }\end{array}$} & IN1 & 0.812 & 0.872 & 0.911 \\
\hline & IN2 & 0.74 & & \\
\hline & IN3 & 0.714 & & \\
\hline & IN4 & 0.765 & & \\
\hline & IN5 & 0.842 & & \\
\hline
\end{tabular}

3.3 Multiple regression analysis

The result of this regression was shown in Table 2. The overall result for the regression model was significant $(p=0.000)$. The adjusted $R$ square is 0.737 which means that all the factors contributed $73.7 \%$ towards the purchase intention of DSs. From the analysis, perceived price (H5) did not contribute significantly to the purchase intention of DSs ( $p=0.102$, $>0.05)$. However, attitude (H1), subjective norm (H2), perceived behavioural control (H3), and health consciousness (H4) contributed significantly to the purchase intention of DSs. The results of the standardized coefficient (beta) revealed that attitude was the most important variable that contributed to the dependent variable (beta $=0.536$ ) followed by perceived behavioural control (beta $=0.366$ ). Besides, the tolerance rate of more than 0.1 and VIF $<10$ showed that each factor tested the different dimensions clearly and without any multi-collinearity problem (Hair et al., 2010).

\section{Discussion}

In this study, H1 is supported. The attitude of consumers toward DSs is important in influencing their intention to purchase DSs. This is consistent with previous studies on purchase intention towards DSs (Wongsawasdi et al., 2016; Alami et al., 2019). Besides, attitude is the most important factor in influencing behavioural intention, especially in DSs purchase intention (Lee et al., 2016; Wongsawasdi et al., 2016).

Based on the results, $\mathrm{H} 2$ is also supported. Similar findings are obtained from previous studies, where family, friends, doctors and advertisements are the most relevant source of knowledge on supplement use (Alnaggar and Chen, 2011). News on the current ongoing pandemic is likely to be the major talking point among consumers (Lee et al., 2016). In addition, H3 is supported which mean perceived behavioural control influences consumer intention to purchase DSs (Noor et al., 2014). Respondents indicated that they are willing to purchase DSs as they believe in the value of DSs and the expectation that these products will improve personal health, especially during the pandemic.

The two new variables added to the TPB model are health consciousness and perceived price. Health consciousness is consumers awareness that purchasing DSs is the best option to enhance one's health (Dickinson et al., 2014). Furthermore, health maintenance was given as the key reason for performing regular physical check-ups and buying health supplement products (Tse et al., 2014). The result in this study showed that there is a significant relationship between health-consciousness and DSs purchase intention during the pandemic. Hence, H4 is supported.

It is also observed that there is an insignificant relationship between perceived price and purchase intention of DSs. One possible explanation for this might be that $75 \%$ of the respondents are in the age category of 21-40 years old. This age group may be unwilling to spend on products with higher prices (Lee et al., 2015). Past studies reported different results in determining perceived price among Malaysians in various aspects especially in the marketing promotion programme. A similar and comparable study on price has shown to be 
Table 2. Results of regression analysis

\begin{tabular}{|c|c|c|c|c|c|c|}
\hline \multicolumn{7}{|c|}{ Coefficients $^{a}$} \\
\hline \multirow{2}{*}{\multicolumn{2}{|c|}{ Model }} & \multicolumn{2}{|c|}{$\begin{array}{c}\text { Unstandardized } \\
\text { Coefficients }\end{array}$} & \multirow{2}{*}{$\begin{array}{c}\text { Standardized } \\
\text { Coefficients } \\
\text { Beta }\end{array}$} & \multirow[b]{2}{*}{$\mathrm{t}$} & \multirow[b]{2}{*}{ Sig. } \\
\hline & & B & $\begin{array}{l}\text { Std. } \\
\text { Error }\end{array}$ & & & \\
\hline \multirow[t]{6}{*}{1} & (Constant) & -1.310 & 0.276 & & -4.748 & 0.000 \\
\hline & Attitude & 0.736 & 0.072 & 0.536 & 10.157 & 0.000 \\
\hline & Subjective Norm & 0.193 & 0.074 & 0.121 & 2.600 & 0.010 \\
\hline & $\begin{array}{l}\text { Perceive } \\
\text { Behavioural Control }\end{array}$ & 0.525 & 0.072 & 0.366 & 7.307 & 0.000 \\
\hline & $\begin{array}{l}\text { Health } \\
\text { Consciousness }\end{array}$ & -0.192 & 0.057 & -0.142 & -3.377 & 0.001 \\
\hline & Perceived Price & 0.078 & 0.047 & 0.065 & 1.643 & 0.102 \\
\hline
\end{tabular}

significant in the purchase intention behaviour of organic food product (Ali Indabawa, 2017). In the current research, perceived price did not show a significant relationship with the purchase intention of DSs during the pandemic outbreak. DSs may be just one of the many preventive options to control disease or illness during this pandemic and some consumers may find that they would rather choose other cheaper alternatives.

This study contributes to the current health-carerelated businesses and pharmaceutical marketing literature. It provides insights to health and medicinal industry stakeholders. In addition, family and friends are an imperative group that is crucial for health supplements users during the pandemic. Advertising information related to the advantages associated with consuming supplements is commonly disseminated through mass and social media. However, if this message is delivered by close family members and friends, this could create a significant impact on their purchase intention (Noor et al., 2014).

The outcome could also be used by dietary advertisers to justify the importance of advertising campaigns to draw customers to their products based on the significant results on attitude and subjective norm. Perceived price is shown to be not significant, therefore marketers could perhaps identify the right product with the right pricing in positioning their dietary product in order to attract more customers. Although the outcome shows that the effect on the pandemic is more significant in terms of spending among the lower and middleincome groups, purchasing intention among the highincome groups remains high (Cox et al., 2020).

Perceived behavioural control demonstrated a significant relationship with general consumers' purchase intention. This may be due to consumers having a mental preference for certain DSs products and its perceived benefits that strengthen their perception of these products. This is further fueled by the growing trend of health consciousness globally. Recognising customer preference and their sense of health consciousness will encourage purchase towards DSs as this is perceived to enhance their overall health objectives.

\section{Conclusion}

Dietary supplements are experiencing robust growth in the industry (Euromonitor, 2019a). Understanding factors that affect the purchase intention towards dietary supplements are important for businesses to build their marketing strategies and to have a more effective targeted marketing campaign. In Malaysia, these posed an opportunity to address some research gaps on factors affecting consumers purchase intention towards DSs. The extended TPB model with integrated health consciousness and perceived price were tested during the COVID-19 outbreak. Multiple regression analysis showed that TPB's variables (i.e., attitudes, subjective norms and perceived behavioural control) together with health consciousness significantly affect purchase intention towards DSs. However, the perceived price was not significantly related to purchase intention. Among the significant factors, attitude is the most influential attribute impacting purchase intention followed by perceived behavioural control. This research contributed significantly to marketers thinking of a new and innovative approach to encourage the purchase of dietary supplements, especially during the pandemic situation.

\section{Conflict of interest}

The authors declare no conflict of interest.

\section{References}

Ajzen, I. (1991). The Theory of Planned Behavior. Organizational Behavior and Human Decision 
Processes, 50(2), 179-211. https://doi.org/ doi.org/10.1016/0749-5978(91)90020-T

Al-naggar, R.A. and Chen, R. (2011). Prevalence of Vitamin-mineral Supplements Use and Associated Factors Among Young Malaysian. Asian Pacific Journal of Cancer Prevention, 12(4), 1023-1029.

Alami, A., Tavakoly Sany, S.B., Lael-Monfared, E., Ferns, G.A., Tatari, M., Hosseini, Z. and Jafari, A. (2019). Factors That Influence Dietary Behavior Toward Iron and Vitamin D Consumption Based on The Theory of Planned Behavior In Iranian Adolescent Girls. Nutrition Journal, 18, 8. https:// doi.org/10.1186/s12937-019-0433-7

Alford, B.L. and Biswas, A. (2002). The effects of discount level, price consciousness and sale proneness on consumer's price perception and behavioral intention. Journal of Business Research, 55(9), 775-83. https://doi.org/10.1016/S0148-2963 (00)00214-9

Ali Indabawa, A. (2017). Factors Influencing Intention to Purchase Organic Dairy Products. Malaysia: Multimedia University.

Alyami, H.S., Orabi, M.A.A., Aldhabbah, F.M., Alturki, H.N., Aburas, W.I., Alfayez, A.I., Alharbi, A.S., Almasuood, R.A. and Alsuhaibani, N.A. (2020). Knowledge About COVID-19 And Beliefs About and Use Of Herbal Products During The COVID-19 Pandemic: A Cross-Sectional Study In Saudi Arabia. Saudi Pharmaceutical Journal, 28(11), 1326-1332. https://doi.org/10.1016/j.jsps.2020.08.023

Birruntha, S. (2019). Dietary Supplement Market Continues Steady Growth Despite Weak Consumer Sentiment. Retrieved from The Malaysian Reserve website: https:// themalaysianreserve.com/2019/07/17/dietarysupplement-market-continues-steady-growth-despite -weak-consumer-sentiment/

Cox, N., Ganong, P., Noel, P., Vavra, J., Wong, A., Farrell, D. and Greig, F. (2020). Initial Impacts of the Pandemic on Consumer Behavior: Evidence from Linked Income, Spending, and Savings Data (July 21, 2020). University of Chicago, Becker Freidman Institute for Economics Working Paper 2020-82. SSRN Electronic Journal. https:// doi.org/10.2139/ssrn.3633008

Dickinson, A., Blatman, J., El-Dash, N. and Franco, J.C. (2014). Consumer Usage and Reasons for Using Dietary Supplements: Report of a Series of Surveys. Journal of the American College of Nutrition, 33(2), 176-182. https:// doi.org/10.1080/07315724.2013.875423

Euromonitor. (2019a). Global Health Trends: Impacts on
Consumers (Issue October). Retrieved from Euromonitor website: http:// www.portal.euromonitor.com.esc-web.lib.cbs.dk/ portal/analysis/tab T4 - Health and Nutrition Survey 2019 Y3 - 13.10.2019 M4 - Citavi

Euromonitor. (2019b). Market Sizes | Historical Geography. Retrieved from Euromonitor website: http://

www.portal.euromonitor.com.ezproxy.eafit.edu.co/ portal/statisticsevolution/index

Ezlika, G., Dilip, M. and Lee, L.C. (2014). Dietary Supplement Users Vs Non-Users In Malaysia: Profile Comparisons For Marketing Purposes. In Proceedings of AGBA 3rd WorldCongress, Advances in Global Business Research, 3(1), 4 - 6 January 2006, p. 43 - 54. Kuala Lumpur, Malaysia.

International Monetary Fund. (2020). World Economic Outlook: The Great Lockdown. April 2020. Retrieved from International Monetary Fung website: https://www.imf.org/en/Publications/WEO/ Issues/2020/04/14/weo-april-2020

Hair, J.F., Black, W.C., Babin, B.J. and Anderson, R.E. (2010). Multivariate data analysis. 7th ed. New Jersey, USA: Prentice Hall.

Lee, J.H., Lim, K.F. and Yong, Y.Y. (2016). Factors Influencing Purchase Intention towards Dietary Supplement Products among Young Adults. Malaysia: Universiti Tunku Abdul Rahman, BSc. Thesis.

Lee, K.H., Bonn, M.A. and Cho, M. (2015). Consumer Motives for Purchasing Organic Coffee: The Moderating Effects of Ethical Concern And Price Sensitivity. International Journal of Contemporary Hospitality Management, 27(6), 1157-1180. https:// doi.org/10.1108/IJCHM-02-2014-0060

Michaelidou, N. and Hassan, L.M. (2008). The Role of Health Consciousness, Food Safety Concern and Ethical Identity on Attitudes and Intentions towards Organic Food. International Journal of Consumer Studies, 32(2), 163-170. https://doi.org/10.1111/ j.1470-6431.2007.00619.x

Noor, N.A.M., Yap, S.F., Liew, K.H. and Rajah, E. (2014). Consumer Attitudes toward Dietary Supplements Consumption: Implications for Pharmaceutical Marketing. International Journal of Pharmaceutical and Healthcare Marketing, 8(1), 626. https://doi.org/10.1108/IJPHM-04-2013-0019

Noh, M., Lee, K., Kim, S. and Garrison, G. (2013). Effects of Collectivism on Actual S-commerce Use and the Moderating Effect of Price Consciousness. Journal of Electronic Commerce Research, 14(3), 244-260. 
Petraszko, H. (2013). Theory of Planned Behavior to Predict Multivitamin/Mineral Use. USA: Eastern Michigan University, MSc. Thesis.

Phillips, M.M. and Rimmer, C.A. (2013). Functional Foods and Dietary Supplements. Analytical and Bioanalytical Chemistry, 405(13), 4323-4324. https://doi.org/10.1007/s00216-013-6846-9

Plank, R.E. and Gould, S.J (1990). Health consciousness, scientific orientation and wellness; an examination of the determinants of wellness attitudes and behaviours. Health Marketing Quarterly, 7(3-4), 6583.

Tan, Y.L., Hoo, W.C., Ng, A.H.H. and Lim, K.Y. (2019). Factor Affecting Purchase Intention of Health Supplement in Malaysia. INTI Journal, 2019, 005.

Tse, M., Chan, K.L., Wong, A., Tam, E., Fan, E. and Yip, G. (2014). Health Supplement Consumption Behavior in the Older Adult Population: An Exploratory Study. Frontiers in Public Health, 2, 11. https://doi.org/10.3389/fpubh.2014.00011

Udomkitmongkol, N. (2016). A Study of Factors Influencing Consumer's Consumption of Dietary Supplement in Bangkok. Thailand: Bangkok University, MBA Thesis.

Wongsawasdi, S. (2016). Consumer Knowledge, Attitude, and Purchasing Behavior on Dietary Supplements for General Health Purpose Among Young Adults in Thailand Consumer Knowledge, Attitude, And Purchasing Behavior on Dietary Supplements for General Health. Thailand: Thammasat University, MSc. Thesis. 